\title{
Environmental quality assessment in Central Andean rivers: using the Ecological Thresholds Concept, Environmental Quality Standards, and Biotic Indexes
}

\author{
HELEN PIMENTEL ${ }^{1}$, Eduardo Oyague ${ }^{2}$, and Edgar Sánchez ${ }^{1}$ \\ ${ }^{1}$ Universidad Nacional Agraria La Molina \\ ${ }^{2}$ División de Limnología CORBIDI Lima Peru
}

September 27, 2021

\begin{abstract}
As in many other countries, Peru has the Water Quality Standard (WQS) as the primary tool for managing and diagnosing water resources. An analysis variable by variable to define water quality as poor or good was applied by setting concentration limits. A second group of tools commonly used are Biotic Indexes based on tolerance of benthic macroinvertebrates to pollution, that reflect the impacts caused by a group of variables, even though they cannot identify which variables determine the viability of the ecosystem. This research proposes to include the Stable States approach to evaluate the ecological integrity in central Andes rivers to explore an alternative approach with the capacity to represent a broader number of factors through multivariate analysis. A ten-year database of biological and physical-chemical variables measured in five Andean rivers were evaluated. Our results suggest these rivers fluctuate into two seasonal stable states (wet and dry season), accounting for approximately $31 \%$ of the system variability. In the wet season, the equilibrium of the state was dominated by the highest levels of suspended solids, turbidity, coliform, phosphorus, and some metals. During the dry season, the key variables were dissolved oxygen, flow, physical habitat, and biotic and diversity indexes. Likewise, there seems to be a third alternative state influenced by human pressures because of variables that exceed the WQS. Regarding water quality, the concentrations of coliforms, phosphorus, and lead usually exceeded the limits in two stations, but not every year. The ecological condition was better represented by ABI index than EPT.
\end{abstract}

\section{Hosted file}

Manuscript_HP_EO_ES-RRA.docx available at https://authorea.com/users/436187/articles/538694environmental-quality-assessment-in-central-andean-rivers-using-the-ecological-

thresholds-concept-environmental-quality-standards-and-biotic-indexes 


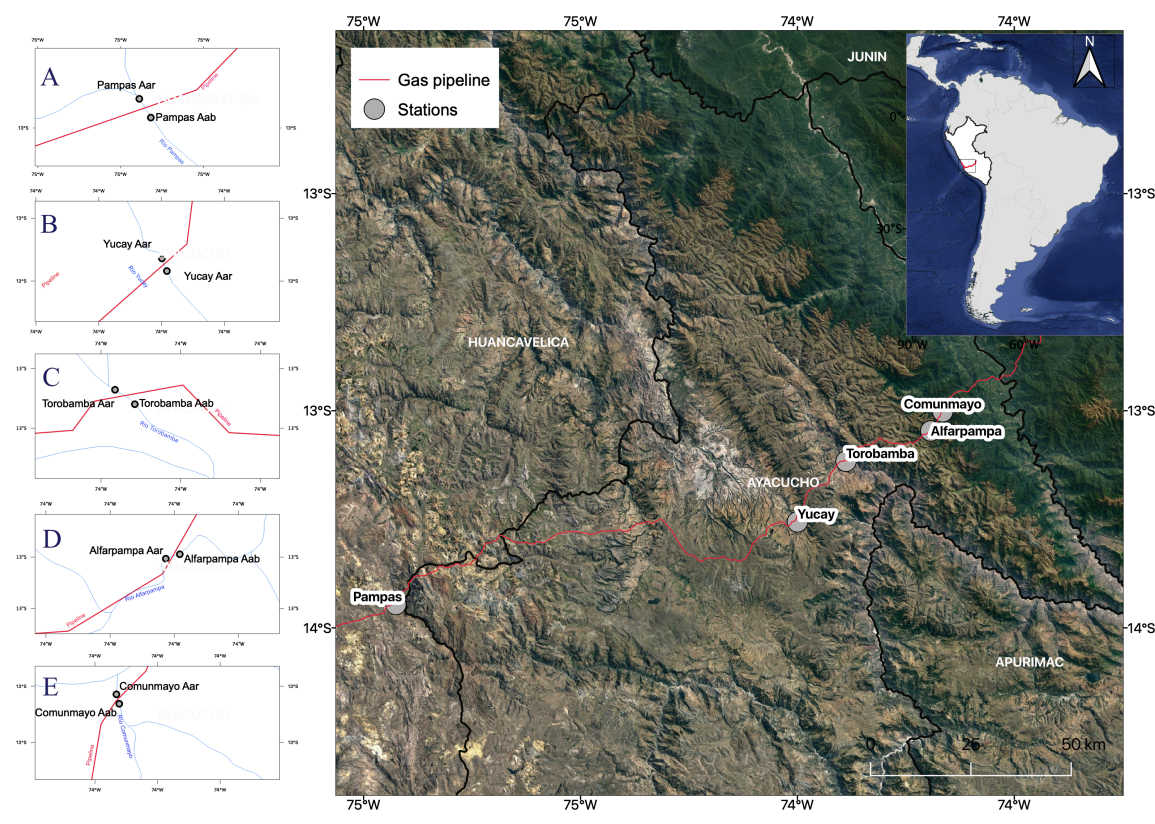



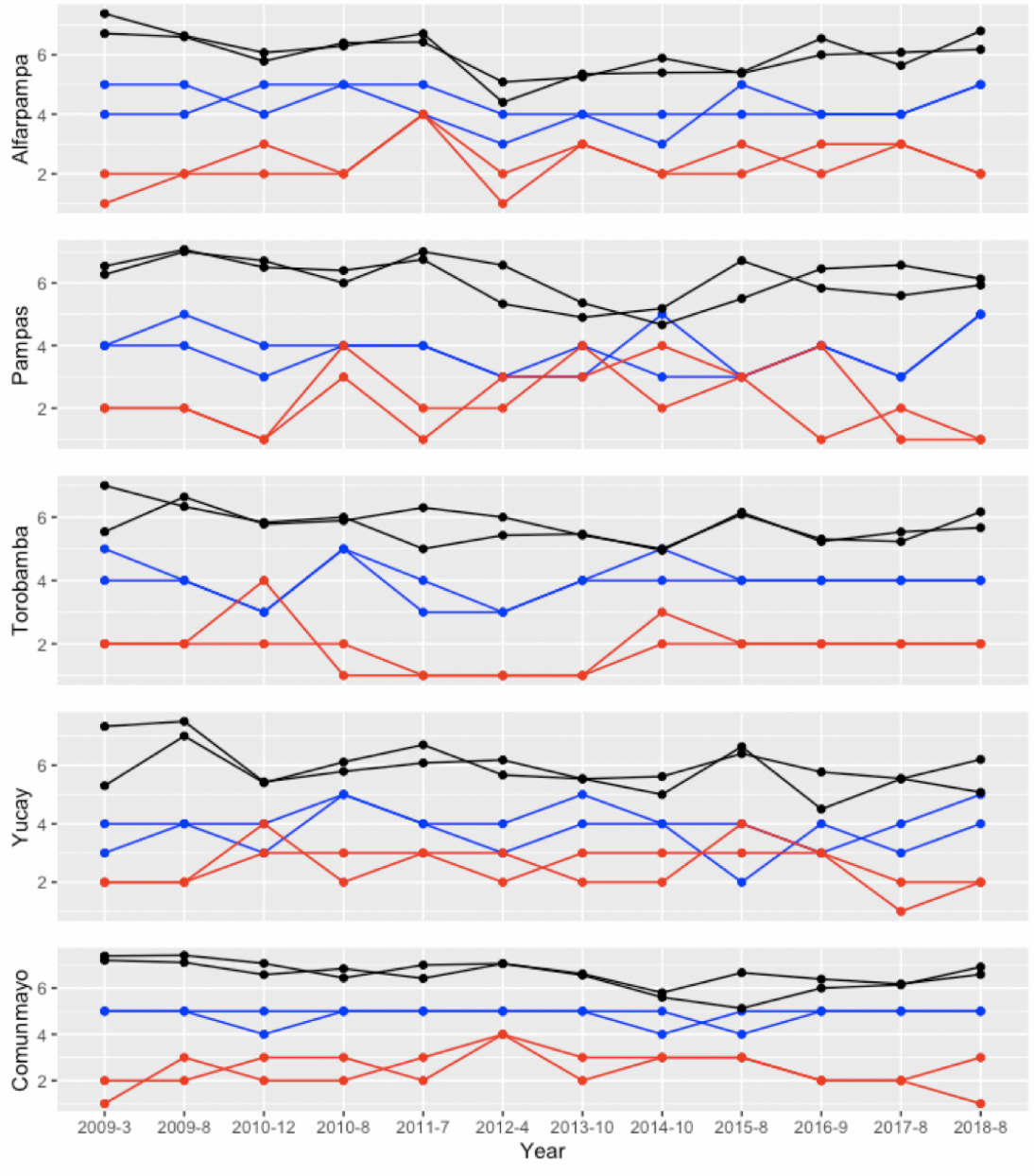

---ABI --- EPT --- ASPT 

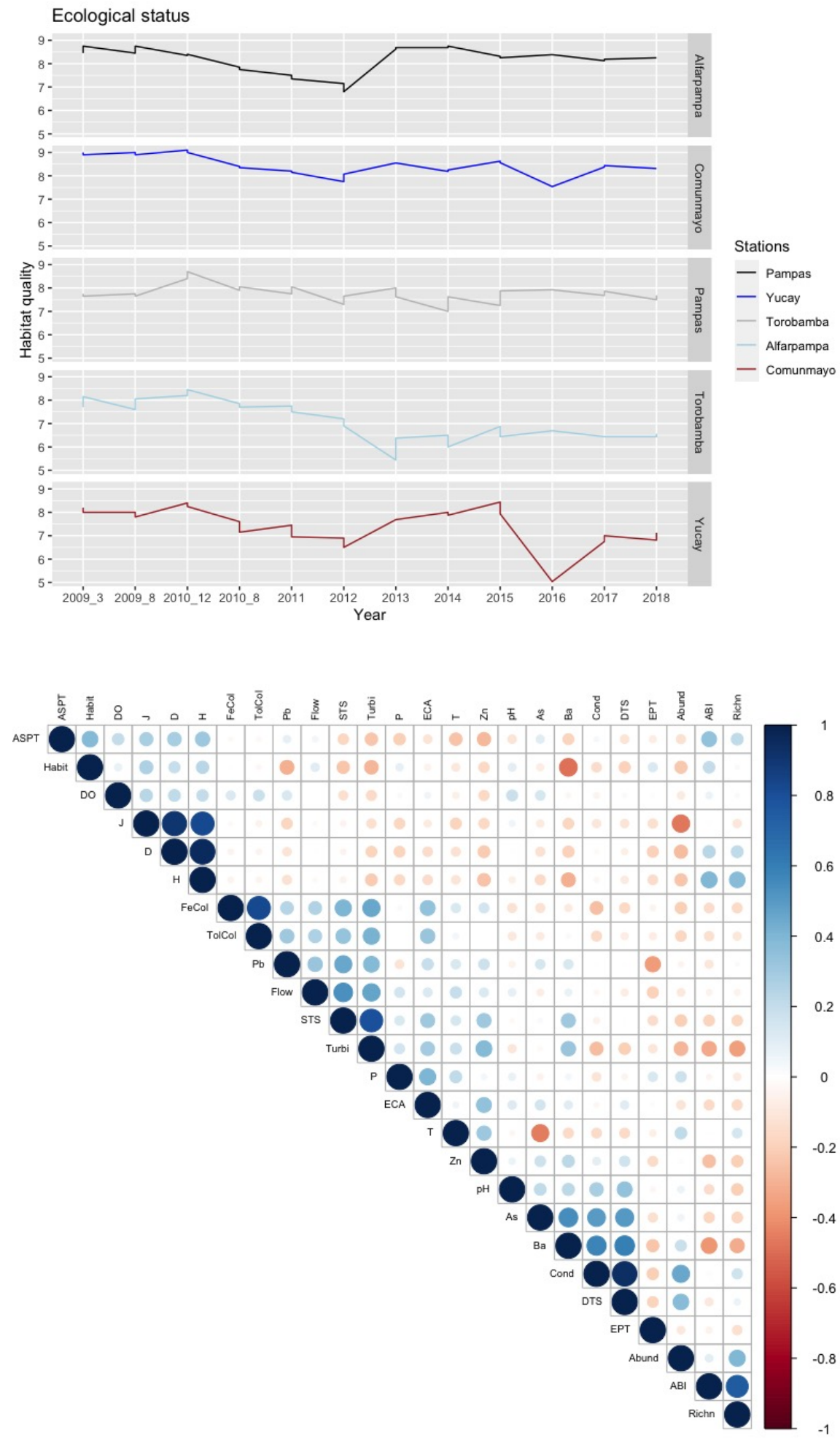


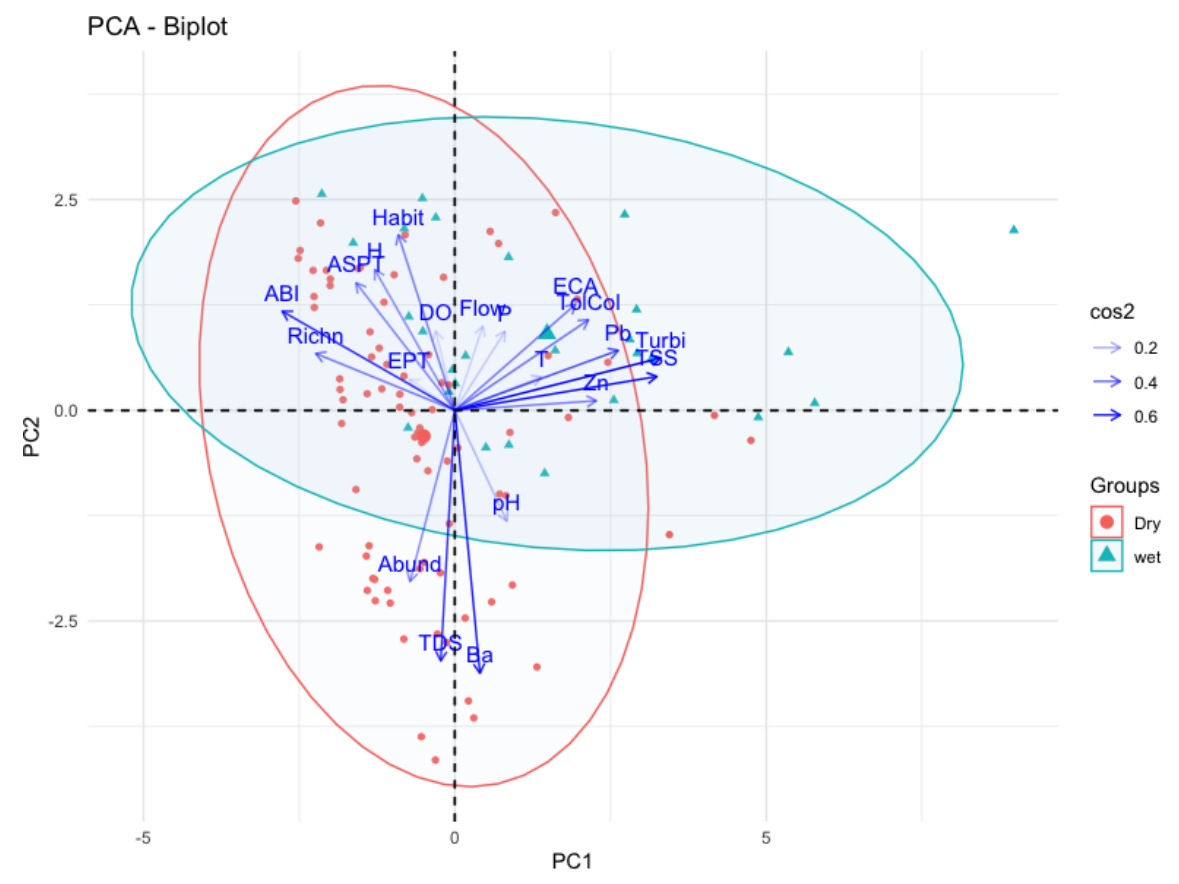

